\title{
LOS NEGOCIOS DE LOS MERCADERES FRANCESCO PINELLI Y DIEGO DE SORIA EN EL ATLÁNTICO MEDIO A FINALES DEL SIGLO XV
}

\author{
Juan Manuel Bello León \\ Instituto de Estudios Medievales y Renacentistas \\ Universidad de La Laguna
}

\section{RESUMEN}

En este trabajo se ofrece la edición de la capitulación que Diego de Soria y Francisco Pinelo firmaron con el nuncio de Su Santidad, Jacobo de Seseńa, para el cobro de la denominada como «Bula de Canaria», destinada a financiar parte de la conquista del Archipiélago. A partir del documento, se describe a sus protagonistas y se intenta demostrar que su intervención en este asunto no fue fruto de la casualidad, sino de intereses mercantiles y financieros que los situaban en una posición inmejorable para ello.

Palabras clave: Canarias siglo xv, mercaderes genoveses, Bula de Cruzada, conquista de Canarias.

\section{MERCHANTS FRANCESCO PINELLI AND DIEGO DE SORIA'S BUSINESS AFFAIRS IN THE MIDDLE ATLANTIC AT THE END OF THE FIFTEENTH CENTURY}

\section{Abstract}

This work offers the edition of the capitulation document signed between the merchants Diego de Soria and Francisco Pinelli and His Holiness Nuncio, Jacobo de Seseńa, whereby the so-called "Canarian Bull" was to be collected in order to partly finance the conquest of the Canarian archipelago. Through the study of the document contents, this work tries to discern these merchants' vested interests in such an operation and describes the very favourable mercantile and financial context which might account for their deliberate intervention.

KeYwords: fifteenth-century Canary Islands, Genoese merchants, Croisade, Conquest of the Canary Islands. 


\section{INTRODUCCIÓN ${ }^{1}$}

En el origen de esta pequeña aportación a este número conmemorativo de la Revista de Historia Canaria quiero que se constate una evidencia que ya ha sido puesta de manifiesto por muchos historiadores. Se trata de lo siguiente: los trabajos dedicados a la conquista y colonización del archipiélago canario son innumerables, por lo que es poco - con las fuentes que hoy conocemos- lo que se puede añadir a lo mucho que vislumbramos sobre aquel acontecimiento. No obstante, sigue siendo posible abordar este proceso desde otros puntos de vista, en este caso profundizando un poco más en el análisis de los vínculos creados entre distintos miembros de la élite mercantil y la Corona para tratar de entender mejor las circunstancias que rodearon la incorporación de las Islas al reino de Castilla. Por tanto, mi objetivo consistirá en intentar reconstruir parte de la historia de esta élite mercantil y diplomática que participó en estos primeros momentos de la expansión por el Atlántico Medio, de tal forma que la descripción de esos grupos de poder -aunque sea de forma somerapermita conocer mejor el entramado social de aquellos que se interesaron por los asuntos de esta región a finales del siglo xv.

Para este propósito voy a utilizar el texto de la capitulación acordada entre los mercaderes Diego de Soria y Francesco Pinelli (Francisco Pinelo) con el legado pontifico Jacobo Rondono y los reyes para el cobro de la llamada Bula de Canaria ${ }^{2}$. Esta última fue un instrumento financiero al que se recurrió para sufragar los gastos del proceso de conquista y evangelización del Archipiélago. No vamos a entrar aquí -ya que se conoce bastante bien- en cuestiones relacionadas con las fechas en las que se comenzó a predicar la bula o el tiempo que mantuvo su vigencia; tampoco en la capacidad recaudatoria, que, por lo que se conoce, parece que fue muy importante ya que se obtuvieron más de un millón de maravedís a lo largo de varios ańos; ni en los pleitos o abusos que acompañaron la predicación de las bulas -tanto la bula de Canaria como las posteriores bulas generales de Cruzada-. Todo ello ha sido analizado por historiadores como Antonio Rumeu, Elías Serra o Eduardo Aznar ${ }^{3}$. Sí que me voy a detener en los protagonistas de este episodio -los

${ }^{1}$ Este trabajo forma parte del proyecto de investigación financiado por el Ministerio de Educación y que lleva por título Solidaridad y/o exclusión en las fronteras marítimas. Castilla en la baja Edad Media (referencia HAR2013-48433-c2-2-p). Abreviaturas utilizadas: AGS=Archivo General de Simancas; AMS=Archivo Municipal de Sevilla; CED=Cédulas.

${ }^{2}$ Desde hace tiempo se conoce bien el nombramiento de Diego de Soria y Francisco Pinelo como receptores de las bulas de indulgencia de Canaria y otros muchos documentos relacionados con su labor como tesoreros y recaudadores, pero, que sepamos, hasta ahora no se ha publicado la capitulación entre ambos mercaderes y el legado pontificio. Aquí ofrecemos la edición paleográfica íntegra de la copia que se sacó en Burgos el año 1503 ante el alcalde de dicha ciudad Alonso de Villanueva y que se encuentra en el AGS. Escribanía Mayor de Rentas, legajo n. ${ }^{\circ}$ 93, fols. 405 y ss.

3 El profesor Rumeu de Armas elaboró varios trabajos al respecto. Véase Rumeu de Armas, Antonio: «La Nunciatura Castellana de Guinea», Revista de Indias, 109-10 (1967) pp. 285-311; «Los problemas derivados del contacto de razas en los albores del Renacimiento", Cuadernos de Historia 1 (1967) pp. 61-103; y La politica Indigenista de Isabel la Católica, Valladolid 1969. Elías Serra abordó 
ya citados mercaderes y el legado pontificio- con el objetivo, como ya he dicho, de demostrar que hubo una serie de personas que, vinculadas por relaciones personales, de parentesco o profesionales, intervinieron en la conquista; participación que no se dio por casualidad, sino que es el resultado de disponer, en aquellos momentos, de un determinado nivel de fortuna, un origen geográfico común o unos oficios que les permitieron a su vez articular una serie de alianzas que hicieron posible su control sobre operaciones financieras destinadas a sufragar los gastos de la conquista.

\section{LOS PROTAGONISTAS}

El primer protagonista del citado documento es uno de los mercaderes más destacados de la península Ibérica a finales del siglo xv. Me refiero al genovés Francisco Pinelo, comerciante que ha dejado un amplísimo rastro documental, lo que ha permitido elaborar varios trabajos sobre sus vínculos familiares y actividades económicas ${ }^{4}$.

Todos los indicios que conocemos de él lo sitúan en Valencia a finales de los años setenta de aquella centuria 5 . Pero sería en Sevilla donde este ligur alcanzó mayor prestigio social e influencia política. Contrajo matrimonio con la cordobesa María de Torres y de su enlace nacieron dos hijos legítimos: Jerónimo y Pedro Pinelo, ambos canónigos de la catedral hispalense. Además, se le conocen otros tres hijos naturales (Cristóbal, Luis y Juan Bautista) y se sabe que falleció en Sevilla en 1509, siendo enterrado en la capilla del Pilar de la citada catedral. Durante su

el tema en su trabajo SERra Ràfols, Elías: «Las indulgencias para la conquista de Canarias», Revista de Historia de Canarias 33 (1970) pp. 64-66. Más próximo a nuestro objetivo es el trabajo de AzNAR Vallejo, Eduardo: "Los inicios de la Bula de Cruzada en Canarias», Revista Española de Derecho Canónico, 44 (1987) pp. 205-219. Véase también Bello León, Juan Manuel: «Notas para valorar la contribución de la expansión atlántica a la Hacienda Real castellana a finales de la Edad Media», Revista de Historia Canaria, 188 (2006), pp. 61-75.

${ }^{4}$ La biografía de Francisco Pinelo y de otros miembros de su familia ha sido trazada en varias ocasiones. Para ello véanse Boscolo, Alberto: «Francesco Pineli amico a Siviglia di Cristoforo Colombo", en Actas del I Coloquio Hispano-Italiano Presencia italiana en Andalucía. Siglos XIV-XVII, Sevilla, 1985, pp. 249-265; D’Arienzo, Luisa: «Francesco Pinelli banchiere del Papa, collettore e nunzio apostolico in Spagna all'epoca di Cristoforo Colombo", en Atti del IV Convegno Internazionale di Studi Colombiani. Génova, 1987; Ybarra Hidalgo, Eduardo: «Notas históricas y genealógicas de la familia Pinelo», Minervae Baeticae, 29 (2001) pp. 9-22; y «Más noticias inéditas de la Familia Pinelo", Minervae Baeticae, 30 (2002) pp. 193-208; Gil Fernández, Juan: Los conversos y la Inquisición sevillana, Sevilla, 2000-2003 (8 vols.) [véase vol. 5.․, p. 65 y ss.]

5 Es importante resaltar la estancia en aquella ciudad mediterránea no sólo porque fue el lugar de entrada de muchos ligures en la península Ibérica sino porque, además, es muy probable que estando en Valencia entrase en contacto con Luís de Santángel, miembro de una familia al servicio de la Corona y que, durante los últimos ańos del siglo xv, tuvo un papel destacado en el control de la tesorería de la Santa Hermandad. Como es bien conocido, y como veremos luego, esta institución jugó un papel muy importante en el control de los recursos que se utilizaron para la guerra contra el reino de Granada y, en algunos casos, para financiar expediciones a Canarias y norte de África. 
larga vida en la ciudad (casi 40 años) llegó a ser jurado y fiel ejecutor, tesorero de la Hermandad, financiero en los primeros viajes colombinos, oficial de la Casa de la Contratación, comendador de la Orden de Santiago y gestor de numerosas rentas de la Corona, especialmente aquellas vinculadas con las almadrabas. Todo ello lo situaba como uno de los comerciantes más importantes del reino, pero de entre los numerosos genoveses que entonces estaban en el entorno de la Corte o en Sevilla ${ }^{6}$, ¿por qué fue Francisco Pinelo el que se interesó por la Bula de Conversión y por los asuntos del Archipiélago? Las circunstancias que podrían explicarlo se encuentran en varios hechos que voy a intentar sintetizar.

En primer lugar, Francisco no fue el único miembro de su linaje que se encontraba en Andalucía en aquellos momentos. Antes de su llegada ya residía en Sevilla un Lorenzo Pinelo - al menos desde 1473-, ya que se le documenta como uno de los genoveses que importaron varias cargas de cereales para abastecer a la ciudad $^{7}$. Casi al mismo tiempo que Francisco tuvo que llegar Castelin Pinelo, documentado en 1477 solicitando, junto a otros mercaderes genoveses, una carta de seguro $^{8}$; se encuentran los hermanos Antonio y Martín Pinelo (este último fraile de Santa María de la Cartuja), documentados en el pago de un cuento de maravedís que la reina exigió a los mercaderes genoveses para contribuir a los gastos del cerco de Baza y en los numerosos pleitos que mantuvieron con distintos vecinos de Sevilla. En los últimos años del siglo xv aparecen Bernardo Pinelo (desde 1486), Luca Pinelo (año 1495) o Jácome Pinelo (desde 1494) ${ }^{10}$. Fuera de Sevilla -en este caso en Cádiz- también se encontraba Benito Pineli, por aquellos años comerciando con Inglaterra y Flandes ${ }^{11}$. Finalmente, el comendador Luis Pinelo -del que desconozco el grado de parentesco con el citado Francisco- obtuvo tierras en el repartimiento de Gran Canaria (seis caballerías de riego); por estos bienes mantuvo un pleito que en 1514 aún no había sido resuelto, ya que ese ańo reclamaba la propiedad ante los incumplimientos del gobernador, Lope de Sosa, y del alcalde mayor, Pedro de Góngora, ya que ambos se habían negado a entregárselas ${ }^{12}$. En fin, parece claro que Francisco Pinelo se rodeó de familiares y allegados que se establecieron en Sevilla atraídos -como otros muchos- por las fuentes de riqueza que hicieron de la ciudad el centro de control del avance castellano por el Atlántico Medio.

${ }^{6}$ Los reyes estuvieron en Sevilla y otras localidades andaluzas la mayor parte de los años 1478 a 1480, coincidiendo con la firma de este documento.

7 AMS. Papeles del Mayordomazgo (13-10-1473). Por esos mismos años también se ha documentado a un Fernando Pinelo.

8 AGS. Registro del Sello, 1-IV-1477. fol. 126; y 20-VII-1478. fol. 69.

9 Algunos ejemplos en AHPS. Protocolos, leg. 9099, fol. 136; fols. 166-167; fol. 180; fol. 273.

10 Bello León, Juan Manuel: «Mercaderes extranjeros en Sevilla en tiempos de los Reyes Católicos», Historia. Instituciones. Documentos, 20 (1993), pp. 47-84.

${ }^{11}$ La hija de Benito -Argentina Pineli-contrajo matrimonio con otro Centurione. En este caso con Martino Centurione.

12 AGS. Cámara de Castilla, CED, 7,133 (18-12-1505); AGS. Registro del Sello, 18-12-1505; Aznar Vallejo, Eduardo: Documentos canarios en el Registro del Sello (1476-1517), La Laguna, 1981, documentos n. ${ }^{\circ} 1042$ (22-6-1514) y n. ${ }^{\circ} 1061$ (14-9-1514). 
En segundo lugar, también está bien documentado que los Pinelo entroncaron desde mediados del siglo XV con otra importante familia de mercaderes genoveses asentados en Castilla: los Centurione. Estos últimos formaban parte de un albergo que extendió su influencia por todo el Mediterráneo y sur de la península Ibérica; se sabe que en la década de los setenta del siglo xv los agentes de los Centurión (entre los que se encontraba Cristóbal Colón) se desplazaron hacia Madeira y costa africana para comprar azúcar y otros productos. Una rama de esta familia, la compuesta por los hermanos Martín, Flérigo y Gaspar Centurión, crearon desde Málaga, Cádiz o Sevilla importantes compañías dedicadas al comercio con la costa africana ${ }^{13}$; otros miembros (Francisco y Domingo Centurión) fueron diplomáticos al servicio de los pontífices en diversos negocios con los Reyes Católicos, además de depositarios de la Cámara Apostólica de la Santa Cruzada. Como luego veremos, Francisco Pinelo también se ocupó de negocios de este tipo, estando en contacto directo con la financiación de los recursos que los monarcas utilizaron para la guerra de Granada o la expansión hacia el Atlántico Medio.

Finalmente, también se sabe que Francisco Pinleo, junto con Manfredo Camila, Doménico Centurione, Jerónimo y Cipriano Gentil, fue uno de los mercaderes italianos establecidos en Castilla a los que se les encomendó la recaudación de las bulas de cruzada, annatas, subsidios y jubileos pertenecientes a la Cámara Apostólica $^{14}$. Aunque las primeras cuentas que conocemos se documentan en 1476, parece que ya desde 1475 se ocupaba de la recaudación ${ }^{15}$; en la amplia relación de gastos e ingresos que se conocen (entre los años 1475 y 1479) se pueden observar, entre otros muchos, dos hechos: primero, que Pinelo se ocupó, sobre todo, de lo recaudado en distintas localidades de la baja Andalucía y, en segundo lugar, que para el desempeño de sus funciones mantuvo relaciones económicas con numerosos comerciantes, entre los que aparece muchas veces Diego de Soria, nuestro siguiente protagonista. Es evidente que en 1480, cuando se firmó el documento que aquí estamos analizando, Francisco Pinelo tenía sobrada experiencia en el cobro de todo lo relacionado con la fiscalidad eclesiástica.

El otro gran personaje de este documento es el mercader burgalés Diego de Soria. Al igual que el ya citado Pinelo, los rasgos básicos de su biografía y de la actividad mercantil que desplegó han sido estudiados en varias ocasiones ${ }^{16}$. Soria,

${ }_{13}$ Un panorama general sobre la actividad de este linaje en la península Ibérica desde finales de la Edad Media y hasta el siglo xviı puede verse en los trabajos de López de Coca Castañer, José Enrique y López Beltrán, María Teresa: «Mercaderes genoveses en Málaga (1487-1516): los hermanos Centurión e Italian», Historia. Instituciones. Documentos, 7 (1980) pp. 95-123; SAnz Ayán, Carmen: Un banquero en el siglo de Oro. Octavio Centurión, el financiero de los Austria, Madrid, 2015.

${ }^{14}$ GonZÁlez JimÉnez, Manuel: «Fiscalidad pontificia e italianos en Castilla (1470-1484)», en La presencia italiana en Andalucía, siglos XIV-XVII. Actas del III Coloquio Hispano-Italiano, Sevilla, 1989, pp. 401-409.

15 Fernández Alonso, Justo: Legaciones y nunciaturas en España de 1466 a 1521, tomo I (1466-1486), Roma, 1963 (véanse p. 278 y ss.)

${ }^{16}$ Hace muchos ańos la profesora Betsabé Caunedo, que es quien mejor conoce a este mercader, lo calificó como «el más poderoso y genuino representante de los mercaderes internacionales» de 
junto con otros mercaderes del Arlanzón, formó parte del grupo de grandes comerciantes vinculados al tráfico internacional y, sobre todo, a las operaciones financieras (préstamos, letras de cambio, depósitos bancarios, etc.). ${ }^{17}$. Casado con Catalina Maluenda, sus hijas - no tuvo descendencia masculina- Beatriz y Leonor de Soria también contrajeron matrimonio con miembros de otras familias de mercaderes burgaleses; Beatriz con Alonso de Lerma y Leonor con Alonso Pardo. Cuando falleció en 1507 dejaba a sus herederos un extenso patrimonio y un prestigio social que quiso inmortalizar con la erección de su propia capilla funeraria en la iglesia de San Gil.

Como en el caso de Pinelo, nos volvemos a hacer la misma pregunta. ¿Por qué Diego de Soria se interesó por los asuntos del Archipiélago en aquellos momentos? La respuesta está, nuevamente, en varias circunstancias. En primer lugar, el interés de los burgaleses por el Atlántico Medio se había manifestado ya desde comienzos del gobierno de los Reyes Católicos ${ }^{18}$. Los hermanos Covarrubias habían desplazado a un factor suyo a Cabo Verde desde 1478 y fueron los burgaleses Álvaro de Medina y Alonso de Tamayo quienes, tras el Tratado de Alcaçovas, se ocuparon del cobro del quinto real de las carabelas procedentes de la costa africana. Finalmente, a otro burgalés -Pedro de Setién- se le encomendó el cobro de las limosnas para la conversión y redención de Guinea y Canarias. Poco antes de la firma del documento que aquí se edita, los reyes encomendaron a este último que entregase a Pinelo y a Soria los maravedís recaudados hasta ese momento. En fin, no es extraño que siendo los burgaleses los mercaderes castellanos más destacados de finales del Medievo, se interesasen por los beneficios que podían proporcionarles las rutas que se estaban abriendo hacia el Atlántico Medio.

En segundo lugar, los vínculos de Diego de Soria con las rentas pontificias se documentan ya desde 1473 y, al menos, hasta 1475 . En el primero de esos años el nuncio Leonoro de Leonori presentaba las cuentas de los ingresos procedentes de la predicación de la cruzada, certificando la entrega de más de 200000 maravedís por parte del banco de Diego de Soria. Poco después, daba cuenta de las prendas y bienes depositados en el banco del citado burgalés para que fueran vendidos por cuenta de la Cámara Apostólica ${ }^{19}$. De nuevo es muy probable que su conocimiento

Castilla. La autora ha tratado su biografía en varios trabajos. Véanse Caunedo del Potro, Betsabé: Mercaderes castellanos en el Golfo de Vizcaya (1475-1492), Madrid, 1983; «Los negocios de Diego de Soria, mercader burgalés", en actas del congreso La Ciudad de Burgos, León, 1985, pp. 163-172; y "Acerca de la riqueza de los mercaderes burgaleses. Aproximación a su nivel de vida", En la España Medieval, 16 (1993) pp. 97-118.

${ }_{17}$ Un panorama general sobre estos aspectos en el trabajo de CAsado Alonso, Hilario: El Triunfo de Mercurio. La presencia castellana en Europa (siglos XV y XVI), Burgos, 2003.

18 Véase Palenzuela Domínguez, Natalia, Los mercaderes burgaleses en Sevilla a fines de la Edad Media, Sevilla, 2003 (especialmente p. 82 y ss.)

${ }_{19}$ Los datos en el trabajo Fernández Alonso, Justo, Legaciones y nunciaturas en España..., ob. cit. (véanse pp. 215 y 227-229). 
de la fiscalidad pontificia, su capacidad financiera y sus relaciones con los legados romanos facilitaran su interés por la bula de Canarias ${ }^{20}$.

El tercer protagonista es el italiano Jacobo Rondono, natural de la villa de Cesena ${ }^{21}$. Llegó a Castilla como legado pontificio en unos momentos de fuerte inestabilidad política y militar en el reino derivada de la guerra de Sucesión; pero también en unos momentos en los que Fernando e Isabel comenzaban a consolidar su poder en el trono ${ }^{22}$. La legación de Cesena fue corta en el tiempo y de pocos resultados políticos y económicos, lo que se ha traducido en un escaso conocimiento de su figura y de su actividad en Castilla. Los datos aportados por Fernández Alonso lo sitúan como miembro de la familia de la aristocracia romana Passarella. Fue secretario apostólico de Sixto IV y desde allí ascendió al obispado de Imola en 1479 para ser, posteriormente, trasladado hasta el de Rímini en 1488.

\section{OTROS PROTAGONISTAS}

Además de los mercaderes Pinelo y Soria, en el documento se menciona a otros personajes que también participaron en la firma de este acuerdo no por casualidad, sino porque, también, mantenían alguna relación con los asuntos del Atlántico Medio desde antes de esta capitulación. Son los casos de Alonso de Quintanilla, el doctor Lillo o el financiero Francisco González Sevilla.

El primero -el asturiano Alonso de Quintanilla- fue uno de los oficiales al servicio de la Corona más destacados de la segunda mitad del siglo $\mathrm{xv}^{23}$. Doncel en

${ }^{20}$ En general, se sabe que distintos mercaderes apellidados Soria se dedicaron desde finales del siglo Xiv al arrendamiento de alcabalas y otras rentas de la Corona. Por tanto, estamos ante una familia que manejó los recursos financieros del reino como medio de proyectar su influencia económica y política en el conjunto de Castilla a finales de la Edad Media. Algunos de estos aspectos han sido estudiados en el trabajo de Guerrero Navarrete, Yolanda: «Hacia una prosopografía de los grupos financieros burgaleses», en Guerrero Navarrete, Yolanda (coord.): Fiscalidad, sociedad y poder en las ciudades castellanas de la Baja Edad Media, Madrid, 2006, pp. 203-239.

${ }^{21}$ Fernández Alonso, Justo: «Nuncios, colectores y legados pontificios en España desde 1474 a 1492», Hispania Sacra, 10 (1957), pp. 59-62.

${ }^{22}$ Las relaciones políticas y culturales entre la España de los Reyes Católicos y Roma han sido analizadas en múltiples ocasiones por lo que me remito a tres trabajos en los que el lector podrá encontrar una amplia información al respecto. Véase la monumental obra de FERNÁNDEZ DE Córdoba Miralles, Álvaro, Alejandro VI y los Reyes Católicos: relaciones político-eclesiásticas (14921503), Roma, 2006; el de Villarroel González, Óscar: El rey y el Papa. Política y diplomacia en los albores del Renacimiento (el siglo XV en Castilla), Madrid, 2010; y el de SERIo, Alessandro: "Por via de capitania e no por via de conduta. Las relaciones entre los Reyes Católicos y la nobleza romana (1494-1530)», en Martínez Millán, J. y Rivero Rodríguez, M. (coords.): Centro de poder italianos en la Monarquía Hispánica (siglos XV-XVIII), Madrid, 2010, vol. I, pp. 77-97.

${ }^{23}$ La biografía del contador mayor y miembro del Consejo Real ha sido estudiada en varias ocasiones desde que en 1909 se publicó el amplio trabajo que hizo Rafael Fuertes. Véanse, entre otros, Fuertes Arias, Rafael: Alfonso de Quintanilla, contador de los Reyes Católicos, Oviedo 1909; Morales MuÑiz, Carmen: Alonso de Quintanilla. Un asturiano en la corte de los Reyes Católicos, Madrid, 1993; AnEs, Gonzalo: «Sobre Alonso de Quintanilla, contador de cuentas y del Consejo de Sus Altezas don 
la corte de Juan II, entró al servicio de Enrique IV con el apoyo de Juan Pacheco, marques de Villena, lo que no impidió que luego tomara partido por el bando isabelino en la lucha que mantuvieron los partidarios del monarca legítimo y de la pretendiente al trono. A partir de entonces, Quintanilla desplegó una frenética actividad militar y administrativa a favor de Isabel, que culminará con su nombramiento como miembro del Consejo Real y con la organización de la Hermandad General. Como es bien conocido, esta institución fue creada para intentar solucionar los numerosos problemas de orden público que afectaban al reino y para proporcionar las bases de un ejército que colaborase en la toma de Granada y en la conquista de Canarias. También es conocido cómo, desde que Alonso de Quintanilla se puso al frente de esta institución, el contador mayor tuvo un papel importante en la organización de las empresas que se dispusieron para la conquista de las Islas a partir de 1480 . Se ha estimado que la Hermandad aportó varios centenares de hombres para la conquista de Gran Canaria, que el propio Quintanilla financió con casi un millón de maravedís las campańas militares y que desempeñó un papel muy destacado en las negociaciones para que se uniesen a la empresa dos experimentados combatientes: el gaditano Pedro Fernández Cabrón y el jerezano Pedro de Vera ${ }^{24}$. Por tanto, de nuevo nos volvemos a encontrar con una persona que en 1480 ya estaba totalmente implicada en los asuntos del Archipiélago, lo que también le llevaría, pasados unos años, a estar en la vanguardia de aquellos que financiaron o apoyaron políticamente las empresas en el Atlántico Medio o en Indias.

Al segundo, el doctor Antonio Rodríguez de Lillo, la historiografía lo conoce muy bien porque tuvo una destacada intervención en la pacificación de Andalucía tras la llegada al trono de Isabel y Fernando y en la implantación de la Hermandad General en el conjunto del reino. Para el caso concreto de los asuntos del Archipiélago, su vínculo más inmediato lo encontramos en la organización de las armadas que, entre 1475 y 1476, se prepararon con destino hacia el Atlántico Medio en el marco de los enfrentamientos navales que mantuvieron Castilla y Portugal por el dominio de este ámbito. Todas ellas han sido analizadas con gran detalle por los profesores Eduardo Aznar o Juan Gil ${ }^{25}$. De sus trabajos se deduce que el doctor Lillo tuvo la capacidad de gestión necesaria como para combinar la participación de naos

Fernando y doña Isabel» en II Congreso de Academias Iberoamericanas de la Historia, Madrid, 1994, pp. 79-94. Nuestro conocimiento sobre el personaje se ha visto notablemente mejorados gracias al hecho de que, hace poco más de 15 años, se pudo localizar y catalogar parte del archivo privado de su familia. Véase SÁnchez del BARrio, Antonio (coord.): El Archivo del Mayorazgo de Alonso de Quintanilla. Fondos documentales conservados en la Fundación Museo de las Ferias (1419-1918), Valladolid, 2009.

${ }^{24}$ Muchas de estas referencias han sido analizadas por Fernández Armesto, Felipe: «La financiación de la conquista de las Islas Canarias en tiempos de los Reyes Católicos», Anuario de Estudios Atlánticos, 28 (1992) pp. 343-377; Lobo Cabrera, Manuel: La conquista de Gran Canaria (1478-1483), Las Palmas, 2012.

25 Aznar Vallejo, Eduardo: «La expedición de Charles de Valera a Guinea. Precisiones históricas y técnicas», En la España Medieval, 25, 2002, 403-423; y Gil Fernández, Juan: «El despacho de la armada de Guinea en 1476», en Vicente Maroto, M. ${ }^{a}$ I. y Esteban Piñero, M. (coord.): La Ciencia y el Mar, Valladolid, 2006, 41-68. 
procedentes de Vizcaya con carabelas que llegaron desde Moguer y Puerto de Santa María, a lo que habría que añadir sus correspondientes tripulaciones.

El tercero, Francisco González de Sevilla, es muy probable que fuera el hijo de Fernand González de Sevilla, escribano mayor de cámara del rey Juan II, escribano de la notaría mayor de Andalucía y recaudador en varias ocasiones de las llamadas rentas menudas, partido incluido dentro del almojarifazgo mayor de Sevilla ${ }^{26}$. Además, se le documenta como escribano mayor de rentas, contador, hacedor de la renta del almojarifazgo y recaudador de alcabalas ${ }^{27}$. También es muy posible que estuviera emparentado con Ruy González Sevilla, mayordomo del concejo hispalense, recaudador del pedido en varias ocasiones, arrendador de diversas imposiciones municipales a mediados del siglo xv y ampliamente documentado en los libros del mayordomazgo sevillano ${ }^{28}$. Y seguro que también mantuvo algún tipo de parentesco respecto a Alfonso González de Sevilla, jurado del concejo y arrendador de la mitad de las denominadas como alcabalas del partido de las mercaderías, cuenta de mercaderes y almonaima, y rentas de Berbería, todas ellas pertenecientes al almojarifazgo mayor de Sevilla ${ }^{29}$. En fin, es evidente que se trataba de una persona vinculada a la gestión de los recursos hacendísticos de la Corona, especialmente con aquellos relacionados con los ingresos que se obtenían por las relaciones con Berbería, lo que, quizás, explicaría que los reyes lo eligieran para que revisara las cuentas de lo que se había recaudado hasta ese momento con la predicación de las indulgencias.

Desde hace ya tiempo varios trabajos han destacado las complejas relaciones existentes entre la red de intereses mercantiles que se generó en Castilla a finales de la Edad Media y su conexión con los intereses políticos de la monarquía, que, a su vez, se entremezclaron con los intereses de instituciones universales como el Papado medieval. En fin, el texto que aquí editamos y la descripción de algunos de los intereses de los protagonistas del mismo nos muestran que, como ya he dicho, lejos de ser una casualidad o un acontecimiento puntual, la participación de algunos

26 Su biografía fue trazada por Cañas Gálvez, Francisco de Paula: Burocracia y Cancillería en la Corte de Juan II de Castilla (1406-1454). Estudio institucionaly prosopográfico, Salamanca, 2012 (véase p. 385 y ss.)

${ }_{27}$ Carande, Ramón y Carriazo Arroquia, Juan de Mata: El Tumbo de los Reyes Católicos del Concejo de Sevilla, Sevilla 1968 (5 vols.). Véase Tumbo; II/230; II/101 y IV/242.

${ }_{28}$ Su labor en la gestión de un importante préstamo (800.000 mrs.) que la Corona solicitó a Sevilla en 1454 y otros datos biográficos (fue padre del también mayordomo Pedro González de Sevilla) pueden verse en el trabajo de Collantes de Terán Sánchez, Antonio: «El mayordomazgo como moneda de cambio por las dificultades económicas del concejo sevillano en la segunda mitad del siglo Xv», Historia. Instituciones. Documentos, 42 (2015) pp. 83-110. Otras referencias en Álvarez García, Carlos: «Un registro de Francisco Fernández de Sevilla, escribano de cámara y contador de hacienda, converso sevillano (1458-1465)", Historia. Instituciones. Documentos, 23 (1996) pp. 1-62.

${ }^{29}$ AGS. Escribanía Mayor de Rentas, leg. 1, fol. 188. 
importantes mercaderes en los inicios de la intervención directa de la Corona en la conquista de Canarias fue un síntoma claro del aprovechamiento de las posibilidades económicas que les abrían a todos ellos las rutas hacia el Atlántico Medio.

Recibido: 06-02-2018, ACEPTAdo: 10-04-2018 


\section{ANEXO}

Copia del año 1503 de la capitulación de Diego de Soria y Francisco Pinelo, con los reyes y con el nuncio de Su Santidad, Jacobo de Seseña, sobre la bula de Cruzada y la conversión y empresa de Canarias.

Archivo General de Simancas. Escribanía Mayor de Rentas. Leg. 93, fol. 405 y ss.

En la muy noble e muy leal çibdad de Burgos cabeça de Castilla ca/ mara del rey e de la reyna nuestros señores, a veynte e cinco días/ del mes de henero año del nasçimiento de nuestro señor Ihesu Xpo de/ mil e quinientos e tres ańos ante el honrrado liçençiado Alon/ so de Villanueba alcalde en la dicha çibdad por el señor (roto)/ García de Cotes corregidor en ella paresçio y presente/ Iohan (roto) en nombre e como procurador que se dixo de Diego de So/ ria (roto) çibdad e mostro e presentó a mi el dicho alcalde una escritura/ de (roto) condiciones firmada de çertos nombres que paresçian ser/ letras (roto) de Quintanilla e de Diego de Soria según por ella/ paresçio, su tenor de la qual es este que sigue/

Las condiciones que por parte del rey e reyna nuestros señores e del reverendo seńor don Jacobo de Sesena/ (...) nuncio de nuestro muy santo padre en los reynos de Castilla e de Aragon e de las Yslas e de (...) / e asymesmo en la conbersyon e santa empresa de la isla de Canaria e de las otras yslas que posee/ los infieles canarios se asentaron e acordaron con Diego de Soria e Françisco Pinelo deposita/ ríos de lo que se cobrare e resçibiere de lo deuido de la yndulgençia e limosna de Canaria e de lo que de aquí ade/ lante se oviere de la predicaçion de la dicha yndulgençia son las siguientes/

\section{Primeramente}

Que su cargo sea aver e cobrar todos los maravedís que por cuenta averiguada se/ fallaren que deuen los tesoreros de lo pasado según la cuenta que se to/ mare por el seńor nuncio e por Françisco Gonçales de Sevilla/de lo qual se les darán obligaciones llanas e liquidas e sy alguna/ costa se ovieren de faser para cobrar lo que asy debe que las fagan a/ vista del dicho señor nuncio e Françisco Gonçales e les sean paga/ das en la forma e manera quellos acordaren e que fagan las deli/ gençias que bien vista les fuere e quede a su juramento sin las aver/ de mostrar en forma/

Yten en lo por venir su cargo sea resçebido de los tesoreros que se nonbraren/ todos los maravedís porque cada uno dellos se obligara antel reverendo/ señor nuncio e Françisco Gonçales de Sevilla, los quales sean teni/ dos tomar tales fianças de los tesoreros que ellos pusieren que sean abo/ nados para aquello porque ellos se obligaren e que sy algunos/ fueren puestos por Diego de Soria e Françisco Pinelo ello/ los abonen e sean a su cargo e que los tales tesoreros de los pues/tos allende a la parte de Burgos sean obligados de poner el dine/ ro en Valladolid e los del arçobispado de Toledo e obispado de Cuenca/ fasta el atajo de toda la Sierra Morena de lo poner en Toledo e los/ de la Sierra Morena adelante con la provincia de Estremadura de/ los poner en Sevilla e que si aquellos tesoreros non cunplieren/ las obligaciones de su recaudança a los plasos a que se obli/garen con dineros e con deligençias que fagan los sobredichos Diego de/ Soria e Françisco Pinelo las diligençias que farian en su mesma fazienda//

Yten por quanto es acordado que la terçia parte de todo lo cobrado/ de la dicha yndulgençia desde quando fue puesto el secresto en los/ dichos dineros por los bienes de nuestro muy santo padre e se cobra/ re de oy en adelante asi de lo debido como de lo que se deviere por la/ nueva percuraçion que se manda fase hayan de acudir con ello quita/ la renta de las costas a muestro muy santo padre e al reverendo se/ ńor nuncio que de presente esta en estos reynos en su nombre que los/ reyes nuestros señores den su fe real de non mandar otra/ cosa sobre ello porque siendo los dichos de po (roto)/ dos por la dicha terçia a la sede apostolica (roto)/ ynobaçion o perturbaçion podrían (roto)/ pero esto se 
faga con tanto que sea (roto)/ retener en deposito la dicha terçia parte (roto) del/ mes de agosto deste año de ochenta dentro del qual termino el/ rey nuestro señor sea tenudo faser traer cerca desto la deter/ minaçion de nuestro señor el papa e que pasado dicho termino los/ depositarios suso dichos recudan con ello al papa o a su man/ dado sino se traxiere la dicha determinaçion de su santidad/

Iten que pues es capitulado con el dicho señor nuncio en nombre/ de nuestro muy santo padre e en nombre del rey e reyna nuestros/ señores por los diputados de sus altesas e del su consejo/ que son Alonso de Quintanilla e los dotores de Talabera e de Li/ llo e de Villalón que todos los maravedís que se ovieren de pagar de la dicha/ negoçiaçion quanto a las dos terçias partes consynadas dela/ conquista e conversión de los infieles canarios se pague/ por libramientos firmados del dicho señor nuncio e de Françis/ co Gonçales de Sevilla deputado por los reyes nuestros señores/ e non por otra forma alguna e que asymesmo ayan de dar sus/ cuentas los dichos depositarios a los sobredichos señor/ nuncio e Françisco Gonçales. E las cuentas quellos a nos apro/ baren sean ynperpetum aprobadas e non sean obligados/ a las dar a contadores mayores de cuentas ni a otros ofiçia/ les algunos salvo en caso que alguno de los sobredichos non/ pudiese por caso fortuito ynterbenir a ellas que en lugar suyo/ sea elegido otro e si faltare el señor nuncio que en su lugar/ por autoridad apostolica sea elegido otro e si el deposita/ rio por los reyes nuestros señores faltaren que sus altesasman/ den deputar otro lo qual piden los dichos depositarios por/ espresaconbençion e que particularmente sea por los reyes/ nuestros señores asy prometido e segurado porque en otra/ manera ellos non tomarían el tal cargo/

Iten que Alonso de Quintanilla les de e faga pagar çien mil maravedís/ de dineros contados en Sevilla dentro de veynte días primeros/ siguientes después de otorgada esta capitulaçion los quales/ el presta para el socorro de la probision que agora se manda/ aser sin que los dichos Diego de Soria e Françisco Pinelo sean/ obligados a la restituçion dellos salvo por renta como ellos/ fueren cobrándolo lo que agora pone de fazienda para este byaje/l

Yten que averiguada la cuenta de lo que Françisco Pinelo ha resçe/ uido e dado e pagado fasta oy e el alcaçe que el fisiere le sea/ librado para que el se encargue dello de lo que se cobrare asi de lo de/ uido como de lo que se predicare entes que otros maravedís algunos des/ pues que fueren pagados los maravedís que agora se ponen para este/ viaje/

Yten (roto) de Quintanilla les aya de dar fianças en quantía/ de (roto) mill maravedís las quales tiene nonbradas que son ale/ (roto) en dozientos mill maravedís a plazo de veynte/ (roto) Castillo e pero Gonçales de palençia por cada/ (roto) mill maravedís e los quales a cada uno dellos sean/ (roto) alguna se obligan a los dichos depositarios por las/ dichas quantías e gelas pagar dende mayo primero de ochenta/ años en cada un año e sy el dicho plazo o antes los dichos Die/ go de Soria e Françisco Pinelo sean satisfechos de todo lo que/ agora ponen para este viaje en tal caso que restituyan las/ dichas obligaciones e sobre dicho Alfonso de Quintanilla/ e que ponga las obligaciones en poder del señor nuncio que las/ tenga fasta la feria de otubre primero siguiente e que sy fas/taentonçe non fueren pagados gelas restituya el señor nun/ çio a ellos/

Yten que si menester ovieren cartas e poderes del rey e reyna nuestros señores/ el dicho señor nuncio para aver e cobrar todos los maravedís de los dichos/ alcances de lo pasado e obligaciones de los advenidero que le se/ ran cargados que ge los darán conplidos e bastantes como ellos los/ demandaren e los hordenaren al dicho dotor de Villalón asymesmo/ les otorga el dicho cargo que non ge lo rebocaran en todo el tiempo/ destanegoçiaçion ni se dara poder a otro alguno para res/ çebir e cobrar. E todos los poderes que fasta agora son/ dados a qualesquier personas sean dados por ninguno/

Yten que por su salario e trabajos ayan de aver cinco por çiento de/ todos los maravedís que resçiviran de lo que es debido de la predicaçion pasada/ e que de la predicaçion futura ayan a seis maravedís por 
çiento el/ qual salario se les da asy por rason de su trabajo e deligençia/ como porque FrançiscoPinelo le obo puesto muchas quantías de maravedís/ de su dinero en la otra espediçion e agora él e Diego de Soria/ prestan otra gran suma e allende desto sendas es/ clabas e sendos esclabos de los primeros que bernan Dios que/ riendo para cada uno dellos dos el qual dicho salario puedan/ asy retener sin otro libramiento alguno por vertuddesta/ capitulaçion/

Yten quedándoles la dicha capitulaçionasi dada e firmada por el/ rey nuestro señor e por el dicho seńor nuncio los dichos Diego de So/ ria e FrançiscoPinelo ayan de conplir e cumplan todas las cosas/ contenidas en el memorial que es firmado de sus nonbres e de los di/ chos deputados en que monta noveçientas e sesetamill maravedís e/ que sean tenudos conplirlos fasta veynte e cinco días de março/ deste año de ochenta a vista del coronista Alonso de Palençia//

Yten que el rey e reyna nuestros señores prometan e den su fes real/y el dicho señor nuncio jure e prometa que non resçibiran ni manda/ ranresçiuir dineros algunos de la dicha negoçiaçionsuso es/ presa mas antes sus altesas e su reuerençia paternidad/ mandaran e aseguraran que todo lo que fallare deuer Pedro de Se/ tien e qualquier otra persona que en estos ayan entendido sea dado/ e entregado a los dichos depositarios Diego de Soria (roto) FrançiscoPinelo/

E questos capítulos suso escritos se acordaron por el reuerendo (roto) Jacobo de Sesena/ eleto de Ymola e por los suso dichos Alonso de Quintanilla e dotores de Talavera e de Lillo e de Villa/ lon del consejo del rey e reyna nuestros señores e por comisione mandado de sus altesas con los di/ chos depositarios Françisco de Pinelo e Diego de Soria. Los quales capítulos va espreso el car/ go que los dichos depositarios toman en si para la recaudança de lo debido de la limosna de la/ yndulgençia de Canaria e de lo que se ouiere de la predicaçion por el salario que les de/ susoconsynado, e baasymesmo declarada la forma que en ello se debe e ha de tener e ge dar/ para que non sea removido nin menoscabada cosa alguna de lo que en los dichos capítulos se/ contiene e que no sean obligados dar cuenta saluo al dicho señor nuncio e a FrançiscoGon/ çales de Seuilla según que de suso en el capitulo que desto fabla se contiene e los quales dichos/ capítulos e cada uno dellos los dichos señores prometieron en nonbre de los dichos señores/ rey e reyna nuestros seńores que lo guardara e les sean guardado e conplido según de suso/ es contenido e concluyose el dicho acuerdo e asyento en Toledo a dos días de febrero de/ mill e quatroçientos e ochenta años e asy mismo el dicho señor nuncio prometio por sy e/ en nonbre de nuestro muy santo padre por vertud de los poderes que tiene de su santidad quitado lo su/ so dicho les sea guardado e conplidosegunt que de suso se contiene. [Con otro tipo de caligrafía] Alonso de Quintanilla. Andrés dotor. Rodrigo dotor, Françisco Pinelo. Diego de Soria.

E asy presentada la dicha escritura ante el/ dicho alcalde luego el dicho Juan de Medina en el dicho nombre dixo al dicho alcalde/ que por quanto el dicho su parte quería lebar o enviar la dicha escritura a algunas/ partes donde por bentura se podría perder por robo o por fuego o por agua/ o por otra cosa forttuyta mayor o menor o ygual donde si asy fuese el/ dicho su parte y el en su nombre resçibirian grande dapño e agravio, por ende/ que pedia e pidió al dicho alcalde que biese e esaminase la dicha escritura e capítulos e/ condiciones e asy visto e esaminada mandase sacar a mi el dicho escribano un/ traslado o dos o masquales e quantos menester obiese e a ellos e a cada uno dello/ el interpusiese su autoridad e decreto para que baliese e fiziese fe donde quier/ que paresçierse como la mesma original. E luego el dicho alcalde tomo la dicha/ escritura en sus manos e dixo que la bia sana e non rota ni escaso algunos/ (...) mas antes caresçiente de todo biçio e sospecha e por ende que manda/ va e mando a mi el dicho escribano que sacase o fisiese sacar de la dicha escritura ho/ reginal un traslado o dos o mas e los quales e a cada uno dellos siendo/ signado del sino de mi el presente escribano el ynterponia e yutapuso su// autoridad e decreto para que valiese e fiziesen fe los dichos treslados e qualquier/ dellosasy como el mismo original e luego el dicho Juan de Medina en el dicho non/ bredixo que lo pedia e pidió por testimonio. Testigos que estavan presen/ tes a lo que dicho es: 
Lope de Horduña e Marcos de Villanueba e Iohan Pardo de/ Soria nieto del dicho Diego de Soria e IohanDespańa criados del señor conde de/ Miranda. Yo Diego de Valladolid escribano de cámara del rey e de la reyna nuestros/ señores (roto) escribano e notario publico del número de la dicha çibdad/ de Burgos (roto) e en todos los sus reinos e señoríos que/ fue presente (roto) es ante el dicho alcalde en uno con los dichos testigos e por/ mandamiento del dicho Juan de Medina en el dicho nonbre e por mandado del dicho su alcalde. [signo notarial] Firma: Diego de Valladolid. 